\title{
Intramolecular Fluorocyclizations of Unsaturated Carboxylic Acids with a Stable Hypervalent Fluoroiodane Reagent
}

\author{
Gemma C. Geary, Eric G. Hope and Alison M. Stuart*[a]
}

\begin{abstract}
A new class of fluorinated lactones was prepared by the intramolecular fluorocyclizations of unsaturated carboxylic acids using the stable fluoroiodane reagent in combination with $\mathrm{AgBF}_{4}$. This unique reaction incorporates a cyclization, an aryl migration and a fluorination all in one step. The fluoroiodane reagent, prepared easily from fluoride, can also be used without a metal catalyst to give moderate yields in just $1 \mathrm{~h}$ demonstrating that it is a suitable reagent for developing new ${ }^{18} \mathrm{~F}$-labelled radiotracers for PET imaging.
\end{abstract}

Fluorinated heterocycles, which are highly-sought after building blocks for the pharmaceutical and agrochemical industries, can be accessed in a single step by the intramolecular fluorocyclization of alkenes. ${ }^{[1]} \gamma$-Butyrolactones are common structural motifs found in a variety of natural products that exhibit a wide range of biological properties (Figure 1). ${ }^{[2]}$ Since the benzyl-substituted $\gamma$-lactones 3 have shown anti-cancer and antiinflammatory activities, ${ }^{[3]}$ new synthetic strategies have been developed for their construction, ${ }^{[3]}$ but as far as we are aware, no-one has prepared any fluorinated analogues.
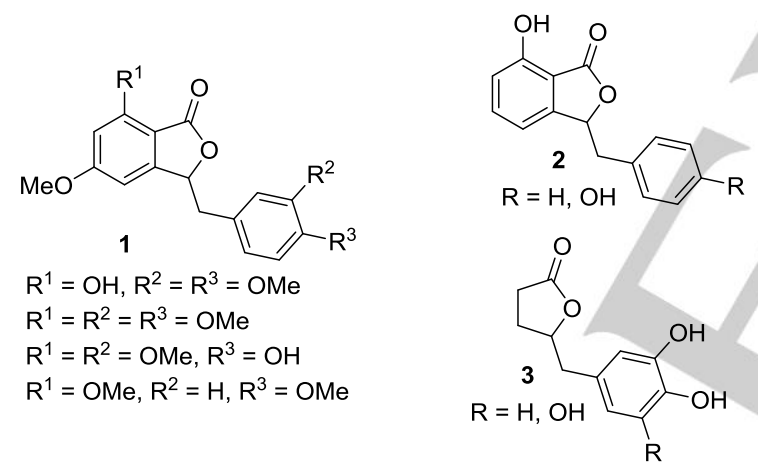

Figure 1. Examples of naturally occurring benzyl-substituted $\gamma$-butyrolactones.

To date, work on the fluorolactonizations of unsaturated carboxylic acids has focussed on using fluoraza reagents in combination with base. ${ }^{[4]}$ These electrophilic fluorinating reagents have also been used successfully for the preparation of fluorinated cyclic ethers and amines via fluoroetherification ${ }^{[5]}$ and aminofluorinations. ${ }^{[6]}$ However, these reagents are normally made from elemental fluorine making them prohibitively expensive for large scale applications. ${ }^{[7]}$ Nucleophilic fluoride sources are much more attractive in terms of cost and for the preparation of ${ }^{18} \mathrm{~F}$-labelled radiotracers for medical diagnostics.

[a] Miss G. C. Geary, Prof. E. G. Hope, Dr. A. M. Stuart,

Department of Chemistry,

University of Leicester,

Leicester, LE1 7RH, UK

E-mail: Alison.Stuart@le.ac.uk

Supporting information for this article is given via a link at the end of the document.
Surprisingly, there has only been one report of a nucleophilic fluorolactonization; difluoroiodotoluene, in the presence of pyridine-6HF, gave fluorinated $\gamma$-lactones in moderate yields (40$50 \%){ }^{[8]}$ In contrast, the intramolecular aminofluorinations of alkenes using nucleophilic sources of fluoride have been wellstudied for the synthesis of 3-fluoropyrrolidines, 3fluoropiperidines and 3 -fluoroazepanes. ${ }^{[9]}$ The disadvantage is that most of these reactions used HF-pyridine which is highly corrosive and has to be handled in specialized Teflon reaction vessels.

As part of our research program on designing new fluorination synthetic strategies, ${ }^{[10,11]}$ we reported the synthesis of the novel fluorinating reagent $\mathbf{4}$ based on the cyclic hypervalent iodine(III) skeleton. The key feature of $\mathbf{4}$ is that it is easily prepared by nucleophilic fluorinations, ${ }^{[11 a, 12 b]}$ but it can simulate electrophilic fluorinations with 1,3-dicarbonyl substrates and styrenes to create new C-F bonds. ${ }^{[11,13]}$ The chelate sidearm makes fluoroiodane $\mathbf{4}$ a much more stable and easy to handle powder compared to the difluoroiodoarenes ${ }^{[8,14]}$ and it can be used in standard laboratory glassware. ${ }^{[15]}$ Earlier this year, Szabó demonstrated that fluoroiodane $\mathbf{4}$ can be used for the intramolecular fluorocyclizations of unsaturated amines, alcohols and malonates in the presence of transition metal catalysts. ${ }^{[13 \mathrm{~b}]}$ In this paper, we report an unusual reaction which combines an intramolecular fluorocyclization with an aryl migration to deliver novel lactones containing a tertiary alkyl fluoride using $\mathbf{4}$ and $\mathrm{AgBF}_{4}$ (Figure 2). In contrast, the fluorolactonizations of unsaturated carboxylic acids with fluoraza reagents are reported to give $\gamma$-lactones containing a primary alkyl fluoride. ${ }^{[4 a, 4 d]}$ Fluoroiodane 4 therefore provides the unique opportunity to prepare fluorinated analogues of benzyl-substituted $\gamma$-lactones which are currently inaccessible with fluoraza reagents.

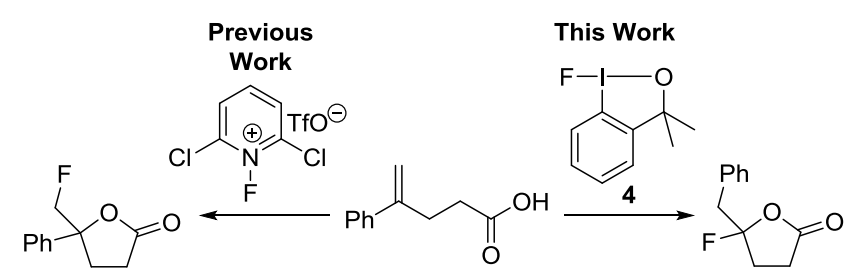

Figure 2. Overview of fluorolactonizations.

To probe the feasibility of an intramolecular fluorocyclization, the preliminary investigation and optimization studies were carried out with 4-phenyl-4-pentenoic acid 5a (Table 1). Treatment of $5 \mathbf{a}$ with fluoroiodane 4 and TREAT-HF at $60{ }^{\circ} \mathrm{C}$ for 24 hours resulted in an encouraging $35 \%$ yield of 5-benzyl-5fluorodihydrofuran-2(3H)-one $\mathbf{6 a}$ (entry 2). However, $\mathbf{6 a}$ was not produced when the fluoroiodane was used without an additive (entry 1) and the addition of KF inhibited the reaction completely (entry 3). In contrast, the introduction of Lewis acids, $\left[\mathrm{Cu}(\mathrm{MeCN})_{4}\right] \mathrm{PF}_{6}$ and $\mathrm{AgBF}_{4}$ catalytically (entries 4 and 5) or 
Table 1. Optimization of fluorocyclization conditions. ${ }^{[a]}$

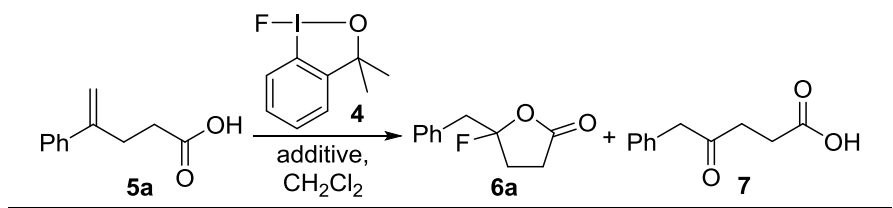

\begin{tabular}{llllll}
\hline Entry & 4 & Additive & Temp. Time & NMR Yield (\%) ${ }^{[\mathrm{b}]}$ \\
\cline { 3 - 4 } & & &
\end{tabular}

\begin{tabular}{|c|c|c|c|c|c|c|c|}
\hline & (eq.) & & $\left({ }^{\circ} \mathrm{C}\right)$ & (h) & $5 a$ & $6 a$ & 7 \\
\hline 1 & 2 & None & 60 & 24 & 0 & 0 & 9 \\
\hline 2 & 2 & $\mathrm{Et}_{3}$ N.3HF (3 eq.) & 60 & 24 & 19 & 35 & 0 \\
\hline $3^{[c]}$ & 2 & KF (3 eq.) & 60 & 24 & 94 & 0 & 0 \\
\hline $4^{[c]}$ & 2 & $\begin{array}{l}{\left[\mathrm{Cu}(\mathrm{MeCN})_{4}\right] \mathrm{PF}_{6}} \\
\text { (0.3 eq.) }\end{array}$ & 60 & 24 & 0 & 0 & 21 \\
\hline 5 & 2 & $\mathrm{AgBF}_{4}$ (0.3 eq.) & 60 & 24 & 0 & 0 & 23 \\
\hline 6 & 1 & $\mathrm{AgBF}_{4}$ (1 eq.) & 40 & 18 & 4 & 0 & 75 \\
\hline 7 & 1 & $\begin{array}{l}\mathrm{AgBF}_{4} \text { ( } 1 \text { eq.), } \\
\text { mol. sieves }\end{array}$ & 40 & 18 & 11 & 76 & 2 \\
\hline 8 & 1.5 & $\begin{array}{l}\mathrm{AgBF}_{4} \text { (1 eq.), } \\
\text { mol. sieves }\end{array}$ & 40 & 18 & 1 & 93 & 6 \\
\hline 9 & 1.5 & $\begin{array}{l}\mathrm{AgBF}_{4}(0.4 \text { eq.), } \\
\text { mol. sieves }\end{array}$ & 40 & 18 & 5 & 86 & 3 \\
\hline 10 & 0 & $\begin{array}{l}\mathrm{AgBF}_{4} \text { (1 eq.), } \\
\text { mol. sieves }\end{array}$ & 40 & 18 & 92 & 0 & 0 \\
\hline $11^{[\mathrm{d}],[\mathrm{e}]}$ & 1.5 & $\begin{array}{l}\mathrm{AgBF}_{4}(1 \text { eq.), } \\
\text { mol. sieves }\end{array}$ & 40 & 1 & 1 & $\begin{array}{c}88 \\
(81)\end{array}$ & 3 \\
\hline
\end{tabular}

[a] Reaction conditions: Substrate $5 \mathrm{a}(0.36 \mathrm{mmol})$, fluoroiodane 4 and the additive were stirred in $\mathrm{CH}_{2} \mathrm{Cl}_{2}(0.2 \mathrm{~mL})$. No solvent was used in entry 2. $4 \AA$ Molecular sieves $(0.09 \mathrm{~g})$ were added to the reaction in entries 7-10. [b] Yield determined by ${ }^{1} \mathrm{H}$ NMR spectroscopy with naphthalene (1.0 eq.) as internal standard. [c] Reaction conducted in $\mathrm{CH}_{3} \mathrm{CN}$. [d] The reaction was scaled up to $0.71 \mathrm{mmol}$ of substrate $\mathbf{5 a}$. [e] Isolated yield in parenthesis.

stoichiometrically (entry 6), generated increasing amounts of 4oxo-5-phenylpentanoic acid 7 (up to $75 \%$ ). We were encouraged by the latter result because 7 was probably formed by the hydrolysis of the competing hydroxy-substituted lactone, 5benzyl-5-hydroxydihydrofuran-2(3H)-one. The addition of $4 \AA$ molecular sieves in entry 7 prevented water competing with fluoride as the nucleophile and changed the reaction completely affording a $76 \%$ yield of the fluorinated lactone 6 a. When 1.5 equivalents of fluoroiodane were used, the yield increased to $93 \%$, but it dropped slightly to $86 \%$ with 0.4 equivalents of $\mathrm{AgBF}_{4}$. As expected, the fluorocyclization of 5 a did not proceed without fluoroiodane 4 (entry 10 ) and the reaction proceeded well in just 1 hour at $40^{\circ} \mathrm{C}$ delivering $6 a$ in an $81 \%$ isolated yield using 1 equivalent of $\mathrm{AgBF}_{4}$ and 1.5 equivalents of fluoroiodane 4 in the presence of $4 \AA$ molecular sieves (entry 11).

The scope of the reaction was probed with a series of unsaturated carboxylic acids and the results are presented in Table 2. The mild reaction conditions were compatible with a number of functional groups on the aromatic ring including
Table 2. Fluorocyclizations with fluoroiodane 4 and $\mathrm{AgBF}_{4}{ }^{[\mathrm{a}]}$

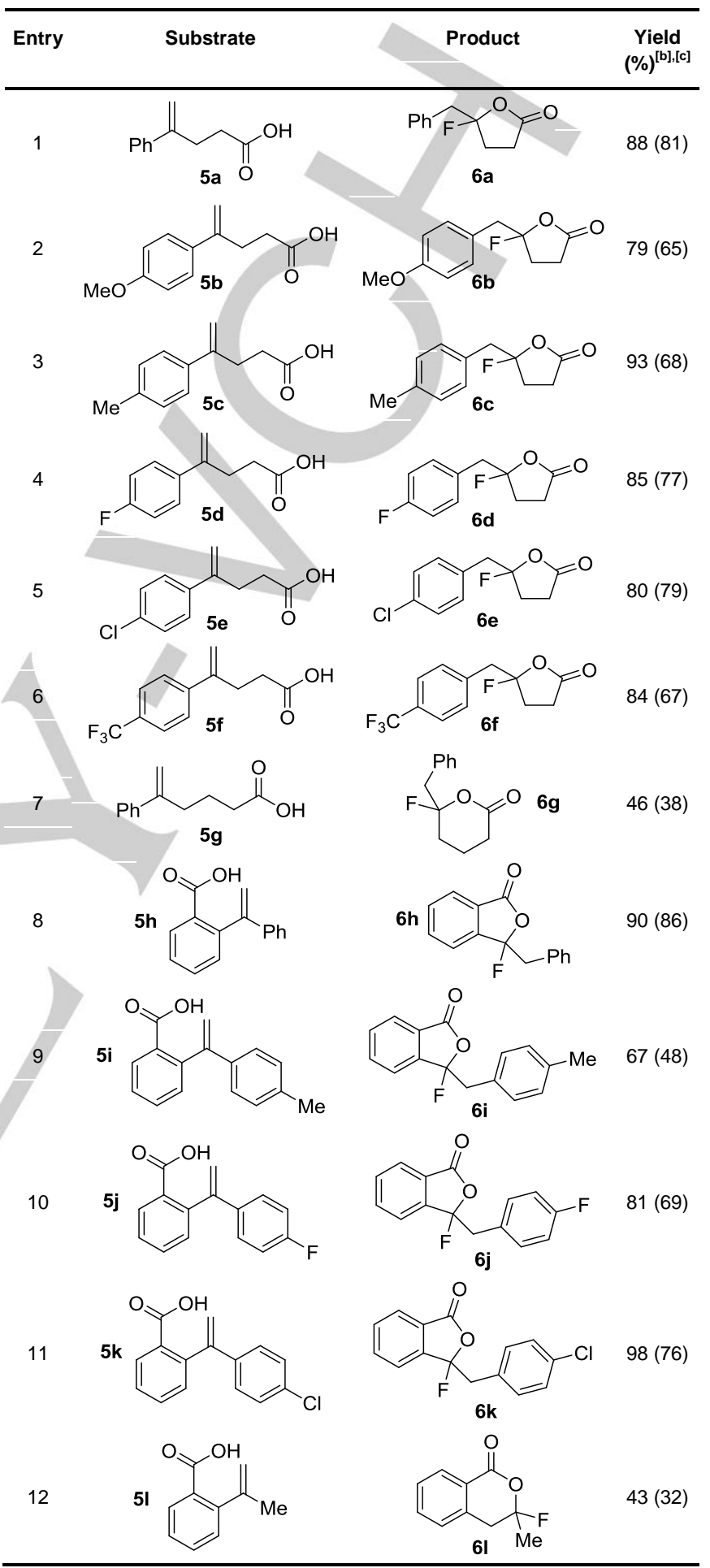

[a] Reaction conditions: Substrate $5(0.7 \mathrm{mmol})$, fluoroiodane 4 (1.1 $\mathrm{mmol})$ $\mathrm{AgBF}_{4}(0.7 \mathrm{mmol})$ and $4 \AA$ molecular sieves $(0.18 \mathrm{~g})$ were stirred in $\mathrm{CH}_{2} \mathrm{Cl}_{2}$ $(0.4 \mathrm{~mL})$ at $40{ }^{\circ} \mathrm{C}$ for $1 \mathrm{~h}$. [b] Yield determined by ${ }^{1} \mathrm{H}$ NMR spectroscopy with naphthalene (1.0 eq.) as internal standard. [c] Isolated yield in parenthesis.

alkoxy (entry 2), alkyl (entry 3), halide (entries 4-5) and trifluoromethyl (entry 6) substituents. The fluorinated lactones 6b-6f were each isolated in high yields (65-79\%) showing that 
the reaction was unaffected by the introduction of either electron-donating or electron-withdrawing substituents onto the aromatic ring. The fluorocyclization of 5-phenyl-5-hexenoic acid (entry 7 ) was also studied to investigate if $\delta$-lactones could be accessed using this methodology, but $\mathbf{6 g}$ was isolated in only a moderate yield (38\%). Isobenzofuranones are privileged structures that appear in numerous natural products and can have useful biological properties. ${ }^{[16]}$ On changing the substrate structure to 2-(1-phenylvinyl)-benzoic acid $\mathbf{5 h}$ in entry 8 , the more electron rich terminal phenyl group underwent the phenyl migration, rather than the aromatic backbone, and the fluorinated isobenzofuranone $6 \mathrm{~h}$ was isolated in $86 \%$ yield. Substitution at the 4-position of the terminal aromatic ring was tolerated well with halides (entries 10-11) giving high yields (69$76 \%$ ), but a slightly lower yield was obtained with the methyl substituent (entry 9). In entry 12, however, the aromatic backbone underwent the phenyl migration resulting in a $\delta$ lactone fused to an aromatic ring 61 . The low $32 \%$ isolated yield was due to elimination problems and formation of the alkene in conjugation with the aromatic ring giving 3-methyl-1Hisochromen-1-one $8 \mathrm{I}$ in $12 \%$ yield (see SI). The novel products generated with fluoroiodane $\mathbf{4}$ are different to those reported from the fluorolactonizations of $\mathbf{5 a}$ and $\mathbf{5 h}$ with electrophilic fluorinating reagents that afforded $\gamma$-lactones containing a primary alkyl fluoride (Figure 3 ). ${ }^{[4 a, 4 d]}$<smiles>C=C(CCC(=O)O)c1ccccc1</smiles>

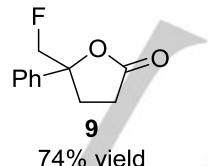

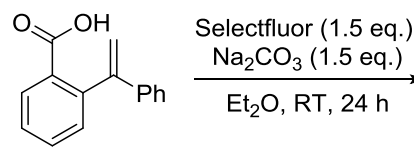

$5 \mathrm{~h}$

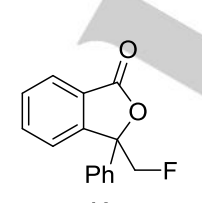

10 $69 \%$ yield
Figure 3. Fluorocyclizations with fluoraza reagents. ${ }^{[4 a, 4 d]}$

The proposed mechanism for the fluorolactonizations is shown in Figure 4 . In the first step the metal catalyst activates the fluoroiodane to form $\mathbf{1 1}$ which undergoes an electrophilic addition to the alkene in $\mathbf{5 a}$ to give the cyclic iodonium intermediate 12. An intramolecular nucleophilic attack of the hydroxyl group occurs at the more substituted carbon because it is better able to stabilise the partial positive charge and is therefore more electrophilic. The $\pi$ donation of the aromatic ring results in the phenonium ion intermediate $\mathbf{1 4}$ with the iodoaryl group acting as an excellent leaving group. Finally, $\mathbf{1 4}$ is ring opened by fluoride resulting in $\mathbf{6} \mathbf{a}$ with fluorination at the quaternary centre. A similar aryl migration has also been reported in the difluorination of styrenes using $\mathbf{4}$ and in the

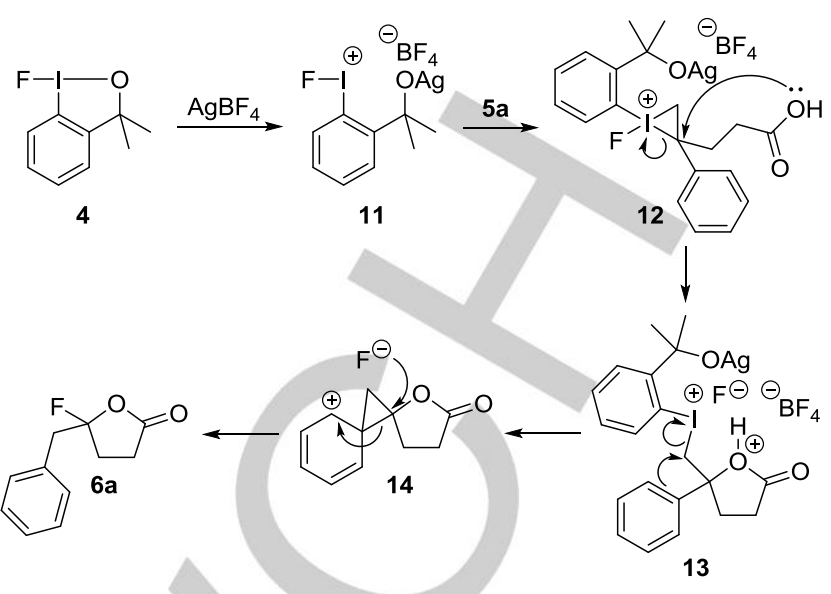

Figure 4. Proposed mechanism for the intramolecular fluorocyclizations.

intramolecular lactonization of $5 \mathbf{a}$ with (diacetoxyiodo)benzene. ${ }^{[13 a, 17]}$ The same mechanism can be used to rationalize all of the results in Table 2 . In compounds $\mathbf{5 h}-\mathbf{5 k}$ the more electron rich terminal aromatic ring underwent the aryl migration, whereas in $\mathbf{5 l}$ the aromatic backbone underwent the aryl migration to form the $\delta$-lactone $6 \mathbf{l}$.

Since $\mathbf{4}$ is easily prepared from simple anionic fluoride salts, it is an attractive reagent for preparing ${ }^{18} \mathrm{~F}$-labelled radiotracers for PET imaging. To explore its potential application for synthesizing ${ }^{18} \mathrm{~F}$-labelled lactones, we further investigated the fluorocyclization of $\mathbf{5 a}$ using molecular sieves as the only additive (Table S1, SI). This would ensure that the fluoride could only be provided by $\mathbf{4}$ and was not coming from the tetrafluoroborate anion of the silver catalyst as reported by Szabó in the difluorination of styrenes. ${ }^{[13 a]}$ Without any metal catalyst we obtained a $63 \%$ yield of $6 a$ (Scheme 1). A short reaction time was essential in view of the short half-life of ${ }^{18} \mathrm{~F}$ (110 $\mathrm{min}$ ) and on reducing the reaction time from $18 \mathrm{~h}$ to $1 \mathrm{~h}$, the yield of 6 a dropped from 63 to $46 \%$ yield (entry 2, Table S1). After further optimisation (see Table S1), the fluorinated lactone 6a was produced in a good $58 \%$ yield in just 1 hour at $40{ }^{\circ} \mathrm{C}$ in acetonitrile using 1.5 equivalents of $\mathbf{4}$ (entry 1 , Table 3 ).

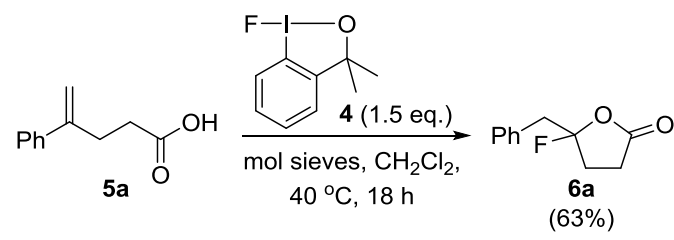

Scheme 1. Fluorocyclization with fluoroiodane 4 and molecular sieves.

This new fluorination protocol was applied to a small series of unsaturated carboxylic acids (Table 3 ). These promising results suggest that the fluoroiodane reagent $\mathbf{4}$ holds great potential for preparing novel ${ }^{18} \mathrm{~F}$-labelled heterocycles and developing new PET tracers that are currently inaccessible with conventional nucleophilic fluorination chemistry. 
Table 3. Fluorocyclizations with fluoroiodane 4 and molecular sieves ${ }^{[a]}$

Entry

[a] Reaction conditions: Substrate $5(0.7 \mathrm{mmol})$, fluoroiodane $4(1.1 \mathrm{mmol})$ and $4 \AA$ molecular sieves $(0.18 \mathrm{~g})$ were stirred in $\mathrm{CH}_{3} \mathrm{CN}(0.4 \mathrm{~mL})$ at $40{ }^{\circ} \mathrm{C}$ for $1 \mathrm{~h}$. [b] Yield determined by ${ }^{1} \mathrm{H}$ NMR spectroscopy with naphthalene (1.0 eq.) as internal standard. [c] Isolated yield in parenthesis.

In conclusion, we have developed a new, mild method for the synthesis of fluorinated lactones using the air and moisture stable fluoroiodane 4 in combination with $\mathrm{AgBF}_{4}$. This unusual reaction combines an intramolecular fluorocyclization with an aryl migration to deliver novel lactones which contain a tertiary alkyl fluoride. In contrast, the same reactions with fluoraza reagents provide lactones containing a primary alkyl fluoride. Furthermore, the fluorination can also proceed without a metal catalyst in $1 \mathrm{~h}$, demonstrating clearly that $\mathbf{4}$ is suitable for the production of new ${ }^{18} \mathrm{~F}$-labelled radiotracers for PET imaging.

\section{Experimental Section}

General procedure with metal catalyst: The substrate $5(0.71 \mathrm{mmol})$, fluoroiodane $4(0.30 \mathrm{~g}, 1.07 \mathrm{mmol}), \mathrm{AgBF}_{4}(0.14 \mathrm{~g}, 0.71 \mathrm{mmol})$ and $4 \AA$ molecular sieves $(0.18 \mathrm{~g})$ were stirred in dichloromethane $(0.4 \mathrm{~mL})$ at 40 ${ }^{\circ} \mathrm{C}$ for $1 \mathrm{~h}$. The solvent was then removed and product 6 was purified by column chromatography.

General procedure without metal catalyst: The substrate $5(0.71 \mathrm{mmol})$, fluoroiodane $4(0.30 \mathrm{~g}, 1.07 \mathrm{mmol})$ and $4 \AA$ molecular sieves $(0.18 \mathrm{~g})$ were stirred in acetonitrile $(0.4 \mathrm{~mL})$ at $40{ }^{\circ} \mathrm{C}$ for $1 \mathrm{~h}$. The solvent was then removed and product 6 was purified by column chromatography.

Keywords: cyclization • fluorine $•$ hypervalent compounds • lactones $\cdot$ silver

[1] a) J. R. Wolstenhulme, V. Gouverneur, Acc. Chem. Res., 2014, 47, 3560; b) G. Liu, Org. Biomol. Chem., 2012, 10, 6243; c) S. C. Wilkinson, R. Salmon, V. Gouverneur, Future Med. Chem., 2009, 1, 847.

[2] a) A. Sari, Natural Product Res., 2010, 24, 56; b) C. Zidorn, S. Grass, E. P. Ellmerer, K.-H. Ongania, H. Stuppner, Phytochemistry, 2006, 67, 2182; c) F. O. Shode, A. S. Mahomed, C. B. Rogers, Phytochemistry, 2002, 61, 955; d) R. Mali, K. N. Babu, P. G. Jagtap, J. Chem. Soc., Perkin Trans. 1, 2001, 3017.

[3] a) M. Peña-López, H. Neumann, M. Beller, Chem. Commun., 2015, 51, 13082; b) C. C. Oliveira, M. V. Marques, M. N. Godoi, T. Regiani, V. G. Santos, E. A. F. dos Santos, M. N. Eberlin, M. M. Sa, C. R. D. Correira, Org. Lett., 2014, 16, 5180; c) H. Qrareya, C. Raviola, S. Protti, M.
Fagnoni, A. Albini, J. Org. Chem., 2013, 78, 6016; d) S. Protti, M. Fagnoni, A. Albini, J. Am. Chem. Soc., 2006, 128, 10670; e) J. D. Lambert, J. E. Rice, J. Hong, Z. Hou, C. S. Yang, Bioorg. Med. Chem. Lett., 2005, 15, 873.

[4] a) D. Parmar, M. S. Maji, M. Rueping, Chem. Eur. J., 2014, 20, 83; b) Y. A. Serguchev, L. F. Lourie, M. V. Ponomarenko, E. B. Rusanov, N. V. Ignat'ev, Tetrahedron Lett., 2011, 52, 5166; c) L. F. Lourie, Y. A Serguchev, G. V. Shevchenko, M. V. Ponomarenko, A. N. Chernega, E. B. Rusanov, J. A. K. Howard, J. Fluorine Chem., 2006, 127, 377; d) M Okada, Y. Nakamura, H. Horikawa, T. Inoue, T. Taguchi, J. Fluorine Chem., 1997, 82, 157

[5] a) D. Parmar, M. Rueping, Chem. Commun., 2014, 50, 13928; b) L. F. Lourie, Y. A. Serguchev, M. V. Ponomarenko, E. B. Rusanov, M. V. Vovk, N. V. Ignat'ev, Tetrahedron, 2013, 69, 833; c) S. C. Wilkinson, O. Lozano, M. Schuler, M. C. Pacheco, R. Salmon, V. Gouverneur, Angew. Chem. Int. Ed., 2009, 48, 7083; Angew. Chem., 2009, 121, 7217.

[6] a) T. Fujiwara, T. Seki, T. Yakura, Y. Takeuchi, J. Fluorine Chem., 2014, 165,7 ; b) L. E. Combettes, O. Lozano, V. Gouverneur, J. Fluorine Chem., 2012, 143, 167.

[7] a) P. T. Nyffeler, S. G. Durón, M. D. Burkart, S. P. Vincent, C.-H. Wong Angew. Chem. Int. Ed., 2005, 44, 192; Angew. Chem., 2005, 117, 196; b) G. S. Lal, G. P. Pez, R. G. Syvret, Chem. Rev., 1996, 96, 1737.

[8] M. Sawaguchi, S. Hara, T. Fukuhara, N. Yoneda, J. Fluorine Chem. 2000, 104, 277.

[9] a) J. Cui, Q. Jia, R.-Z. Feng, S.-S. Liu, T. He, C. Zhang, Org. Lett., 2014, 16, 1442; b) S. Suzuki, T. Kamo, K. Fukushi, T. Hiramatsu, E. Tokunaga, T. Dohi, Y. Kita, N. Shibata, Chem. Sci., 2014, 5, 2754; c) W. Kong, P. Feige, T. de Haro, C. Nevado, Angew. Chem. Int. Ed., 2013, 52, 2469; Angew. Chem., 2013, 125, 2529; d) Q. Wang, W. Zhong, X. Wei, M. Ning, X. Meng, Z. Li, Org. Biomol. Chem., 2012, 10, 8566.

[10] a) M. Fornalczyk, K. Singh, A. M. Stuart, Chem. Commun., 2012, 48 , 3500; b) M. Fornalczyk, K. Singh, A. M. Stuart, Org. Biomol. Chem., 2012, 10, 3332.

[11] a) G. C. Geary, E. G. Hope, K. Singh, A. M. Stuart, Chem. Commun. 2013, 49, 9263; b) G. C. Geary, E. G. Hope, K. Singh, A. M. Stuart, RSC Adv., 2015, 5, 16501.

[12] a) C. Y. Legault, J. Prevost, Acta Crystallogr. Sect. E, 2012, 68, 01238 ; b) V. Matoušek, E. Pietrasiak, R. Schwenk, A. Togni, J. Org. Chem., 2013, 78, 6763 .

[13] a) N. O. Ilchenko, B. O. A. Tasch, K. J. Szabó, Angew. Chem. Int. Ed., 2014, 53, 12897; Angew. Chem., 2014, 126, 13111; b) W. Yuan, K. J. Szabó, Angew. Chem. Int. Ed., 2015, 54, 8533; Angew. Chem., 2015, 127, 8563.

[14] a) T. Kitamura, S. Kuriki, M. H. Morshed, Y. Hori, Org. Lett., 2011, 13 2392; b) M. A. Arrica, T. Wirth, Eur. J. Org. Chem., 2005, 395; c) M. Sawaguchi, S. Ayuba, S. Hara, Synthesis, 2002, 1802.

[15] The thermal stability of fluoroiodane $\mathbf{4}$ and some of its precursors were investigated using differential scanning calorimetry (Table S2, SI) and the results show that it is safe to use 4 up to $100{ }^{\circ} \mathrm{C}$.

[16] R. Karmakar, P. Pahari, D. Mal, Chem. Rev., 2014, 114, 6213

[17] A. C. Boye, D. Meyer, C. K. Ingison, A. N. French, T. Wirth, Org. Lett., 2003, 5, 2157 


\section{Entry for the Table of Contents}

Layout 2:

\section{COMMUNICATION}

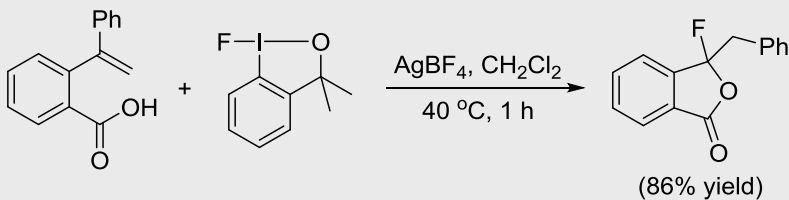

A new class of lactones containing a tertiary alkyl fluoride were prepared in high yields by a combined intramolecular fluorocyclization and an aryl migration using the stable fluoroiodane reagent.
Gemma C. Geary, Eric G. Hope and Alison M. Stuart*

Page No. - Page No.

Intramolecular Fluorocyclizations of Unsaturated Carboxylic Acids with a Stable Hypervalent Fluoroiodane Reagent 